\title{
Agency, Narrative, and Mortality
}

\author{
Roman Altshuler
}

\begin{abstract}
[Forthcoming in Luca Ferrero (ed.), Routledge Handbook for the Philosophy of Agency]
\end{abstract}

According to reductionism a la Parfit (1984), personal identity consists of psychological states bound together over time by psychological continuity. Similarly, causalism in the philosophy of action holds that an action is simply an event, typically a bodily movement, caused by mental states such as beliefs and desires. Narrative accounts offer a response to this reductionism in both domains. The basic idea is that narratives can incorporate a wide range of heterogeneous states, processes, and events as well as shape them. Most narrativists espouse a kind of holism on which the building blocks of lives and actions are structured by those lives and actions themselves.

\section{Narrative}

Since the function of narrative is to unite heterogeneous elements-motives, actions, circumstances-what makes it a fruitful philosophical tool is ironically the slipperiness of the concept. Is the narrative connection primarily emotional (Velleman, 2003) or causal (Carroll, 2007)? While narrative is more than a simple list of events, is the difference one of kind or degree (Currie, 2010)? I will largely eschew these concerns and focus on a key point of agreement: 'the most salient feature of narrative form in general is that the individual incidents and episodes in a narrative take their meaning from the broader context of the story in which they occur' (Schechtman, 1996, p. 96). Since the meaning of the whole depends on how the narrative turns outwhether a story is one of triumph or failure will depend on whether the 
Hobbits destroy the ring-it follows that the meaning of earlier events is fixed by later events.

Some narrativists present narrative as constitutive of personal identity, envisioning an entire life as embodying a single overarching narrative (Dennett, 1992; MacIntyre, 2007; Rudd, 2007). Recent theorists have often switched tactics, in part following Christine Korsgaard's response to Parfit to emphasize the role of agency in self-constitution. While Parfit holds that persons can be described metaphysically in impersonal terms as involving causal relations between their psychological states, Korsgaard defends a firstpersonal and practical conception. Although we have conflicting motives, we have only one body; thus, we cannot simply act on our motives, but must select which ones to act on, on the basis of reasons we commit to. In order to lead a life, that is, to act on motives such that we don't constantly trip over ourselves, we must be able to commit to future goals. 'You normally think you lead one continuing life because you are one person, but according to this argument the truth is the reverse. You are one continuing person because you have one life to lead' (Korsgaard, 1989, p. 113). Our identity is thus not a metaphysical matter, but a practical one, and what unifies our agency is our set of agential commitments or practical identity, 'a description under which you value yourself, a description under which you find your life to be worth living and your actions to be worth undertaking' (Korsgaard, 1996, p. 101). Marya Schechtman (1996), meanwhile, has argued for a distinction between questions of reidentification and questions of characterization. The former have to do with identifying a person as the same being at different times. The latter deal with such questions as survival, moral responsibility, and selfdirected concern. She views narrative as constitutive of the latter rather than the former sort of identity. Discussions of narrative have consequently largely-though not entirely-moved to a focus on its role in agency and practical identity. 
This is a salutary shift. Narrative conceptions of personal identity, insofar as they aim to oppose reductionism, run into a number of problems, which can be summarized under the headings of the Accretion Objection and the Fragmentation Objection (Altshuler, 2015a). According to the former, on a reductionist view, the future becomes a mere causal upshot of the past. If we think of the self as constituted by causal chains of psychological states, then the future is nothing more than a series of effects, leaving our agency-which narrative was meant to bring in-out of the picture. The suggestion of narrative identity theories is that narrative introduces something over and above psychological states, namely, the whole in light of which the elements must be interpreted. When thinking of self-constitution, this translates roughly to the idea that my sense of who I am and what I must do to be that sort of person shapes how I interpret and react to my past. Thus, it is my agency, rather than simply the force of my accreted past, that shapes who I am. But it isn't clear how narrative helps with this: it is, after all, still my past that shapes my future. I may interpret and react to my past on the basis of my conception of my future, but isn't that conception itself simply a product of the past?

The Fragmentation Objection has several variants. One is the claim that selfnarratives are prone to self-deception (Lippitt, 2007; Strawson, 2004). While narrativists can respond that self-deception is not a problem for narrative as such —we just need better narratives (Rudd, 2007)—the underlying problem is that narratives necessarily involve self-deception, precisely because, if narrative is to have a unity, it must exclude all features of a life that don't fit. Consider Harry Frankfurt's $(1992,1982)$ theory of identification. Frankfurt argues that we are responsible for our actions when we identify with the firstorder desires that lead to those actions, and thus we aim to establish a unified will by identifying with some desires and excluding others as foreign. But, as David Velleman (2002) notes, this looks like a recipe for disaster: the desires we refuse to identify with continue to operate on us, but now outside of our 
ability to reign them in. Narrative accounts of personal identity seem to fall prey to the same problem. A better narrative won't help since any unified narrative, by virtue of its unity, will necessarily exclude some elements of our identity, which nevertheless continue to shape it.

The two objections reinforce each other. In responding to the Accretion Objection, narrativists argue that narrative shapes our identities, over and above the causal features of our lives, and it is the unity of narrative that gives it its significance (Malpas, 1998). But this response runs into the Fragmentation Objection: any attempt to impose such a unity will of necessity leave out features of our identity and thus cannot be constitutive of that identity. If the narrativist responds to the Fragmentation Objection by insisting that we need better narratives capable of incorporating all the elements of our identities, we run into the Accretion Objection: attempts to incorporate all such elements will destroy the narrative's unity, so that once again our past becomes an accretion of events that do not cohere with each other, propelling us into the future through sheer causal force. The strongest response seems to be to abandon the idea that narrative constitutes our metaphysical identities, and instead emphasize its role in practical identity. Although all elements of my past play some role in my identity, I must choose some, form a coherent and unified narrative from them, and rely on it to shape my agency. This refocuses us on the extent of narrative's participation in our agential self-constitution.

\section{Agency}

Perhaps the most straightforward role for narrative in agency is developed by Peter Goldie in relation to Michael Bratman's planning theory. Bratman argues that our agency contains three core features: 'We are reflective about our motivation. We form prior plans and policies that organize our activity over time. And we see ourselves as agents who persist over time' (Bratman, 2000, 
p. 35). Goldie aims to show that 'there is something very important that makes narrative thinking a natural way of doing these things' (Goldie, 2009, p. 101). This 'something very important' is the multiplicity of perspectives narrative allows. In telling narratives we display not only the emotions of their characters, but also the emotions we take to be appropriate to the telling; the audience, in turn, may have different emotions altogether.

After a night out, full of confidence, a 23-year-old me attempts jumping a fence and rips his favorite jeans. In remembering my confidence retrospectively, I remember the episode as shameful and regret my bravado; in response to such regret, I envision a narrative in which I walk around instead, and I experience satisfaction at this image. Goldie's point is that it is the emotional structure of narrative that allows for this interaction of emotions: the confidence I feel in the narrative of my past, the shamefulness with which I present it to myself in the narrative, the regret I experience in envisioning it, the calm I attribute to myself in the future, and the satisfaction I feel in relation to it. This emotional structure is key to planning, but it also makes reflectiveness unnecessary. If reflectiveness allows us to endorse policies that guide our future actions, Goldie argues that the emotional force that drives us to adopt narratives for future agency can dispense with such policies: through narrative's emotional power, we can inculcate virtuous character traits, making certain actions unthinkable, and reflective policies designed to block them otiose. Meanwhile, by creating these links between past and future agency, narrative allows us to grasp ourselves as beings that exist over time.

In this account, narrative is only a tool, though without narrative such agential capacities would require more thought and likely be vastly reduced. But narratives also provide context for exercises of agency, as shown by Velleman's account of scenarios, which specify how to carry out various kinds of social moves. In visiting a post office, for example, I may wait in line, fill out a form, and walk up to the window, and I may improvise the details of these 
moves. I cannot, however, present my lunch or a lecture on Hegel, at least not if I want to send a piece of mail. 'The scenario doesn't supersede the ordinary psychological factors in explaining the agents' behavior... indeed, it incorporates them' (Velleman, 2009, p. 74). My desire to send a piece of mail is certainly part of the explanation for my waiting in line and approaching the teller's window with a filled-out form; but it is the scenario, together with that desire, that explains my action. Velleman doesn't claim that scenarios have a narrative form, but it's reasonable to treat them as such: the desired outcome structures the antecedent steps, prescribing how the characters within the story are to move. And while desires are part of the explanation, most desires-especially ones like a desire to send a piece of mail-themselves have narrative explanations.

Narratives may thus tap into our motivational structure while providing a background understanding of the social world within which motivation unfolds. Narratives also provide a background understanding of our own histories, values, capacities, and aspirations, and guide our agency via that combination. As Alasdair MacIntyre noted, 'we identify a particular action only by invoking two kinds of context, implicitly if not explicitly. We place the agent's intentions... in causal and temporal order with reference to their role in his or her history; and we also place them with reference to their role in the history of the setting or settings to which they belong' (MacIntyre, 2007, p. 208). In MacIntyre's view, we cannot understand human actions without narratives, because actions can be explained only via intentions, and we cannot understand those intentions without narratives that place them within the contexts of a culture and an individual life: whether a man gardening is doing so to please his wife or to prepare for winter will depend on two different sorts of narratives-one of spousal relations, and one of a 'household-cum-garden setting' (MacIntyre, 2007, p. 206).

This picture is also key to Schecthman's Narrative Self-Constitution View, according to which 'a person's identity is created by a self-conception that is 
narrative in form' such that 'constituting an identity requires that an individual conceive of his life as having the form and the logic of a story' (Schechtman, 1996, p. 96). We make sense of our past and future via narratives, and we use those narratives to guide our actions, thus constituting our selves. For example, a person who has lived through the Great Depression and one who was raised in times of plenty are likely to treat their finances very differently. MacIntyre held that in explaining an action, we need to place it in the context of an entire life, since it is from the whole that the part draws its significance. Schechtman adapts this view-dropping MacIntyre's insistence that life must be oriented toward the good-that every action must derive its significance from an implicit narrative sense of a whole life (Schechtman, 2011). I may want to start my morning with coffee without a further thought, for example, but if questioned why, I can mention my poor sleep habits, a desire to finish some writing, and a recollection of several months in which I cut out coffee with unfortunate results for my research. Each of these explanations, in turn, has ties to other aspects of my life-aspirations, career ambitions, daily habits, a coffee-less experience abroad-each of which will have further such links.

Not everyone believes that a narrative explanation of this kind, 'an explanation of a mental state or action [that] connects that mental state/action to the subject's sense of himself, of where he has been and where he is going (or trying to go)' (Schroer and Schroer, 2014, p. 457), must tie into a sense of a whole life. Lumsden and Ulatowski, for example, adopt Schecthman's view with the caveat that such connections take place only within individual 'narrative threads', allowing us to act in very different ways in the context of, say, a first date and a job interview, such that 'within the person there are different stories running in the two situations, where each story provides not only a distinct history of events but also a distinct set of themes, vocabularies, descriptions, values, and associated emotional color' (Lumsden and Ulatowski, 2017, p. 320). On their view, narrative self-constitution applies within each 
role we play, but switching between such narratives is largely an unconscious process, not reliant on some meta-narrative. This disunity of self thesis, however, may find difficulty explaining how concepts we utilize in our practical deliberation are narratively inseparable from elements across these different narrative threads (Malpas, 1998). While I may want a beer, both the desire for a beer and what would count as an object of this desire are, for me, shaped by a wide range of other desires, past experiences, and future aspirations (yes, aspirations, as indeed each beer must be logged into an app!). Thus, while it is probably true that there is no meta-narrative of a whole life in the same sense in which we might think of an action or pattern of actions having narrative form, it seems unlikely that the narrative threads governing different patterns of action could coexist without extensive narrative links to each other, and thus without some narrative sense that allows us to mediate between them. Indeed, insofar as these distinct threads can provide divergent perspectives on the same content, they allow for revision of our practical identities going forward (Atkins, 2008, p. 76).

Narrative may also help structure action internally. Narratives make agents' motives intelligible, but action itself may have a narrative form, since actions are shaped by their aim as narratives are by their conclusion (Carr, 1991, pp. 61-62). Furthermore, the connections necessary for practical reasoning that concludes in action seem to also have a narrative form. Beliefs and proattitudes do not typically fit so tightly together that an action necessarily follows from them; rather, they share themes with each other and with the proposed action, and these themes fit together in the form of a narrative (Bevir, 2000). Velleman proposes another role for narrative. First, via their emotional import, they can provide a level of self-understanding running parallel with causal-psychological self-understanding. On Velleman's view, self-understanding is a constitutive aim of agency: in order to act we must act on attitudes that make us coherent to ourselves and act on them because they make us coherent to ourselves (Velleman, 1992). Insofar as narrative provides 
self-understanding, it can guide our agency. Although Velleman states that narrative self-understanding may be 'supplementary' and 'optional' (Velleman, 2009, p. 203), he elsewhere gives it a central role in our selfgovernance: a narrative self-understanding can provide an agent with a rationale of how to act next while preserving coherence (Velleman, 2006, p. 219). ${ }^{1}$

For Velleman, narrative can also explain why the value of a life seems to depend not simply on the sum of momentary well-being in that life, but on its shape. A life that begins with failure and slowly leads to success seems more desirable, especially if the success is a result of learning from failure, than a life that goes the other way, even if the latter has the same well-being overall. Velleman's suggestion is that this difference is due to the more satisfying narrative the first sort of life affords (Velleman, 2000). John Fischer develops this idea, noting the distinctive feature of narratives, 'that later events can alter the "meaning" or "significance" of earlier events. In this sense narratives can have "loops"... It is not that we can change the physico-causal past; but we can sometimes change its meaning and thus its contribution to the value of our lives overall' (Fischer, 2009, p. 147). On this picture, every action has the potential to change the significance of past events, and the value of acting freely lies in the ability to redeem the past. Horace Pippin took up painting in order to strengthen his arm, wounded in the First World War. The resulting display of talent and vision can serve to cast the wound in a more positive light.

If narratives play a crucial role in explaining an agent's motivation and the connection between motivation and action, as well as between an individual action and the wider project or life in which it is embedded, and we accept that 'loops' are central to narratives, narrative may give us far more power over our past than simply the ability to change its emotional significance (Altshuler, 2015b). While some of our motives are simple-an itch causes me to scratch it-others are far more complex, and thus require complex narratives. And 
since narratives function by creating unity out of heterogeneous events, they specify motives not simply by attempting to recapture the various physiological, emotional, and conative events that occurred in an agent prior to action, but by picking out the relevant ones. Thus, if we want to provide a causal-psychological account of any given complex action, we cannot do so without narratives, and the motives we arrive at are at least partially constituted by those very narratives. In understanding ourselves and others, we do so through narratives that explain the meaning of actions by specifying what motives could make sense of both the action and the various psychological, physiological, and social events that preceded it. But since the meaning of events in a narrative depends on later events, the precise motives that led to an action will depend partially on the action they in fact lead to, and the actions will derive their meaning partially from their consequences and the projects of which they are a part, which in turn will depend on the life or narrative thread within which they occur. Part of what it means to be an agent, then, is to have the ability, through one's actions, to determine, and perhaps reconfigure, one's own motivational and psychological past.

\section{Mortality}

The concept of death that emerges from a narrative view cannot be a biological one. Imagine an author constructing a narrative. She painstakingly crafts her characters, putting them in complex situations and giving them multifaceted goals. In one scene, they are relaxing on the eve of battle, but the author suffers a devastating loss and never returns to her story. The narrative ceases without a conclusion. We might say that it stops, but it does not end.

The biological concept of death seems like the wrong sense of ending here. At least, it seems to have little meaning for narrative theorists, except in the sense that it represents a point at which our narratives are entirely taken over by others (Sartre, 2012, pp. 695-696). If death is going to be meaningful from a 
narrative perspective, it has to mean more than cessation. Heidegger makes some helpful distinctions here: first, death is not a stopping in the sense in which a road or rain stop. Second, it is not simply a 'perishing', or the cessation of biological processes. Nor is it a 'demise', or the sense in which we know we will one day stop living and leave behind bodies mourned by others (Heidegger, 1996, pp. 244, 247). ${ }^{2}$ In distinguishing death from all these biological, cultural, and psychological senses, Heidegger's aim is to bring out death's significance within the context of any human life rather than provide an analysis of it.

For the narrative theorist, such significance could view death as a telos, the summation of life. Relatedly, death may be seen as the prospective conclusion in light of which the meanings of our lives take shape. ${ }^{3} \mathrm{~A}$ narrativist account might thus suggest that death is necessary for life to have a meaning. After all, if the elements of a life derive their meaning from interconnections, and thus no part of a life can be understood apart from the whole, there cannot be meaning unless the boundaries are in view, and one of those boundaries is set by death. Without endings, Fischer (2009, p. 157) suggests before launching a rebuttal, our lives would lack narrative structure and thus the meaning it affords. This view that an immortal life would be meaningless finds its classic defense in Bernard Williams (1973).

Williams's argument famously proceeds along the following lines: there are two options for immortality. One possibility is that an immortal's character goes on changing, just as it does in the course of an ordinary life, such that over time the person becomes unrecognizable to her past self. Another possibility is that one's character remains constant and thus an immortal life would eventually result in interminable boredom. The reason immortality would grow boring, for Williams, seems to be that we would run out of categorical desires-desires that are not conditional on whether or not we remain alive. Such categorical desires are closely tied to our projects and commitments 
(Altshuler, 2013), and one might think that without them, nothing could make our lives meaningful to us.

A defense of Williams suggests two possibilities: first, an endless life would be shapeless, and thus impossible to evaluate for its desirability (Altshuler, 2015c; Burley, 2009); second, the very values by means of which we evaluate lives are themselves constitutively dependent on mortal lives (Malpas, 1998; Nussbaum, 1989; Scheffler, 2013). Williams's critics respond that immortal lives need not be shapeless: they can gain a shape from their projects, which create their own (typically overlapping) narratives (Chappell, 2009; Ferrero, 2015; Fischer, 2009). These local narratives, in turn, can allow for the finitude necessary to sustain value. Such responses would seem a natural fit for Lumsden and Ulatowski's version of narrative disunity. But while these narratives can guide action in particular domains and support values internal to them, it is less clear that they can equally well support values that seem to have a global place within life.

Much of the debate proceeds as if the narrative functions of shaping and guiding agency were intrinsic to agency as such, and thus could be adapted to different kinds of agents. But the ubiquity of narrative may be an adaptation to our mortality rather than an accompaniment. Consider the suggestions developed by Velleman and Fischer, that a life's value depends on its narrative shape, and that the value of acting freely lies in our ability to redeem our past. It is relatively clear why, given our limited life-spans, we might employ narrative forms of thinking in order to maximize those lives' values. But in an endless life, redeeming the past is a pointless task, and once an overall narrative is no longer possible, it is less obvious that local narratives can maintain their cohesion. Part of Galen Strawson's critique is that any view that plays up the ubiquity of narrative in life will be either too strong to be believable or too weak to be informative (Strawson, 2004). It will either define narrative such that practically no one qualifies as possessing one or makes narrativism trivially true-if simply acting on a desire requires a narrative, the 
thesis that narrative permeates human life becomes vapid. Without some overall guidance from a global narrative, the role of narrative might degrade to this trivial condition. Why use a complex cognitive mechanism to temporally organize one's life when such temporal organization is unnecessary? One response is that opportunities for action will present themselves to immortals as well as mortals. But whether immortals have reason to care about such opportunities remains an open question. Perhaps we derive meaning from narratives within our mortal lives, but it is only mortal lives that make room for such narratives. 


\section{References}

Altshuler, R., 2015a. Teleology, Narrative, and Death, in: Stokes, P., Lippitt, J. (Eds.), Narrative, Identity and the Kierkegaardian Self. Edinburgh University Press, Edingburgh, pp. 29-45.

Altshuler, R., 2015b. Free will, narrative, and retroactive self-constitution. Phenom Cogn Sci 14, 867-883.

Altshuler, R., 2015c. Immortality, Identity, and Desirability, in: Cholbi, M. (Ed.), Immortality and the Philosophy of Death. Rowman \& Littlefield, Lantham, MD, pp. 191-203.

Altshuler, R., 2013. Practical Necessity and the Constitution of Character, in: Herrera, C.D., Perry, A. (Eds.), The Moral Philosophy of Bernard Williams. Cambridge Scholars Publishing, Newcastle, pp. 40-53.

Atkins, K., 2008. Narrative Identity and Moral Identity: A Practical Perspective, 1 edition. ed. Routledge, New York.

Behrendt, K., 2016. Learning to Be Dead: The Narrative Problem of Mortality, in: Cholbi, M. (Ed.), Immortality and the Philosophy of Death. Rowman \& Littlefield, Lantham, MD, pp. 157-172.

Bevir, M., 2000. Historical Explanation, Folk Psychology, and Narrative. Philosophical Explorations 3, 152-168.

Bratman, M., 2000. Reflection, Planning, and Temporally Extended Agency. The Philosophical Review 109, 35-61.

Burley, M., 2009. Immortality and Meaning: Reflections on the Makropulos Debate. Philosophy 84, 529.

Carr, D., 1991. Time, Narrative, and History. Indiana University Press, Bloomington, Ind.

Carroll, N., 2007. Narrative Closure. Philosophical Studies 135, 1-15. Chappell, T., 2009. Infinity goes up on trial: must immortality be meaningless? European Journal of Philosophy 17, 30-44.

Currie, G., 2010. Narratives and Narrators: A Philosophy of Stories. Oxford University Press.

Davenport, J.J., 2012. Narrative Identity, Autonomy, and Mortality: From Frankfurt and MacIntyre to Kierkegaard, 1 edition. ed. Routledge, New York.

Dennett, D.C., 1992. The Self as a Center of Narrative Gravity, in: Kessel, F.S., Cole, P.M., Johnson, D.L. (Eds.), Self and Consciousness: Multiple Perspectives. Lawrence Erlbaum, Hillsdale, NJ.

Ferrero, L., 2015. Agency, Scarcity, and Mortality. Journal of Ethics 19, 349378.

Fischer, J.M., 2009. Free Will, Death and Immortality: The Role of Narrative, in: Our Stories: Essays on Life, Death, and Free Will. Oxford University Press, New York.

Frankfurt, H., 1992. The Faintest Passion. Proceedings and Addresses of the American Philosophical Association 66, 5-16. 
Frankfurt, H., 1982. Freedom of the Will and the Concept of a Person, in: Free Will. Oxford University Press, New York.

Goldie, P., 2009. Narrative Thinking, Emotion, and Planning. The Journal of Aesthetics and Art Criticism 67, 97-106.

Heidegger, M., 1996. Being and Time. SUNY Press, Albany.

Korsgaard, C., 1996. The Sources of Normativity. Cambridge University Press, Cambridge.

Korsgaard, C., 1989. Personal Identity and the Unity of Agency: A Kantian Response to Parfit. Philosophy \& Public Affairs 18, 101-132.

Lippitt, J., 2007. Getting the Story Straight: Kierkegaard, MacIntyre and Some Problems with Narrative. Inquiry 50, 34-69.

Lumsden, D., Ulatowski, J., 2017. One Self per Customer? From Disunified Agency to Disunified Self. The Southern Journal of Philosophy 55, 314-335.

MacIntyre, A.C., 2007. After virtue: a study in moral theory. University of Notre Dame Press, Notre Dame, Ind.

Malpas, J., 1998. Death and the Unity of a Life, in: Solomon, R.C., Malpas, J. (Eds.), Death and Philosophy. Routledge, New York, pp. 120-134.

Nussbaum, M.C., 1989. Mortal Immortals: Lucretius on Death and the Voice of Nature. Philosophy and Phenomenological Research 50, 303-351.

Parfit, D., 1984. Reasons and Persons. Oxford University Press, Oxford.

Rudd, A., 2007. In Defence of Narrative. European Journal of Philosophy 17, 60-75.

Sartre, J.-P., 2012. Being and nothingness: an essay on phenomenological ontology. Washington Square Press, New York.

Schechtman, M., 2011. The Narrative Self, in: Gallagher, S. (Ed.), The Oxford Handbook of the Self. Oxford University Press, Oxford.

Schechtman, M., 1996. The Constitution of Selves. Cornell University Press, Ithaca, NY.

Scheffler, S., 2013. Death and the afterlife. Oxford University Press, Oxford.

Schroer, J.W., Schroer, R., 2014. Getting the story right: a Reductionist narrative account of personal identity. Philos Stud 171, 445-469.

Strawson, G., 2004. Against Narrativity. Ratio XVII, 428-452.

Velleman, J.D., 2009. How We Get Along. Cambridge University Press, New York.

Velleman, J.D., 2006. The Self as Narrator, in: Self to Self. Cambridge University Press, Cambridge, pp. 203-223.

Velleman, J.D., 2003. Narrative Explanation. The Philosophical Review 112, $1-25$.

Velleman, J.D., 2002. Identification and Identity, in: Contours of Agency: Essays on Themes from Harry Frankfurt. MIT Press, Cambridge, MA, pp. 91-123.

Velleman, J.D., 2000. Well-Being and Time, in: The Possibility of Practical Reason. Oxford University Press, New York, pp. 56-84.

Velleman, J.D., 1992. What Happens When Someone Acts? Mind 101, 461481. 
Ward, D., 2019. Moving Stories: Agency, Emotion and Practical Rationality, in: Candiotto, L. (Ed.), The Value of Emotions for Knowledge. Springer International Publishing, New York, pp. 145-176.

Williams, B., 1973. The Makropulos case: reflections on the tedium of immortality, in: Problems of the Self. Cambridge University Press, New York, pp. 82-100.

\section{Additional Readings}

Ricoeur, P., 1992. Oneself as Another. University of Chicago Press, Chicago.

Along with Ricoeur's earlier work on narrative, this is a founding source for work on narrative identity.

Hutto, D. (Ed.), 2007. Narrative and Understanding Persons. Cambridge University Press, Cambridge.

A collection of important essays by both prominent critics and proponents of narrative identity.

Atkins, K., Mackenzie, C. (Eds.), 2008. Practical Identity and Narrative Agency. Routledge, New York.

Key work in the transition from a focus on metaphysical to practical identity, with a helpful introduction.

Stokes, P., 2015. The Naked Self. Oxford University Press, Oxford.

Critically examines how Kierkegaard can shed light on narrative and identity.

\footnotetext{
${ }^{1}$ Against Velleman's claim of a supplementary role for narrative, see Altshuler (2015b) and Ward (2019).

${ }^{2}$ Page numbers refer to the standard German edition.

${ }^{3}$ For discussion of the mortality problem for narrativism, see Chapter 5 of Davenport (2012).

Behrendt (2016) argues that mortality poses no special problem for narrative accounts.
} 